\title{
Vitamin D and schizophrenia: 20 years on
}

\author{
Xiaoying Cui ${ }^{1,2} \cdot$ John J. McGrath $\mathbb{1}^{1,2,3} \cdot$ Thomas H. J. Burne ${ }^{1,2} \cdot$ Darryl W. Eyles $\mathbb{C}^{1,2}$
}

Received: 15 September 2020 / Revised: 17 December 2020 / Accepted: 11 January 2021 / Published online: 26 January 2021

(c) Crown 2021. This article is published with open access

\begin{abstract}
Many epidemiological studies have highlighted the link between vitamin D deficiency and schizophrenia. In particular, two prominent studies report an association between neonatal vitamin D deficiency and an increased risk of schizophrenia. In parallel, much has been learnt about the role of vitamin D in the developing central nervous system over the last two decades. Studies in rodent models of developmental vitamin D (DVD)-deficiency describe how brain development is altered leading to a range of neurobiological and behavioral phenotypes of interest to schizophrenia. While glutamate and gamma aminobutyric acid (GABA) systems have been little investigated in these models, alterations in developing dopamine systems are frequently reported. There have been far more studies reporting patients with schizophrenia have an increased risk of vitamin D deficiency compared to well controls. Here we have conducted a systematic review and meta-analysis that basically confirms this association and extends this to first-episode psychosis. However, patients with schizophrenia also have poorer general health, poorer diets, are frequently less active and also have an increased risk of other medical conditions, all factors which reduce circulating vitamin D levels. Therefore, we would urge caution in any causal interpretation of this association. We also summarize the inconsistent results from existing vitamin D supplementation trials in patients with schizophrenia. In respect to animal models of adult vitamin D deficiency, such exposures produce subtle neurochemical alterations and effects on cognition but do not appear to produce behavioral phenotypes of relevance to schizophrenia. We conclude, the hypothesis that vitamin D deficiency during early life may increase the risk of schizophrenia remains plausible and warrants ongoing research.
\end{abstract}

\section{Introduction}

Two decades ago, we first hypothesized that low levels of maternal vitamin D increased the risk of schizophrenia [1]. This hypothesis was originally based on "ecological" epidemiology (e.g. season of birth studies), but is now supported by analytical epidemiological studies demonstrating that neonates with vitamin D deficiency have an

Supplementary information The online version contains supplementary material available at https://doi.org/10.1038/s41380021-01025-0.

Darryl W. Eyles

eyles@uq.edu.au

1 Queensland Brain Institute, University of Queensland, St. Lucia, QLD 4072, Australia

2 Queensland Centre for Mental Health Research, The Park Centre for Mental Health, Wacol, QLD 4076, Australia

3 National Centre for Register-Based Research, Aarhus University, 8000 Aarhus, Denmark increased risk of developing schizophrenia later in life $[2,3]$. Animal models of developmental vitamin D (DVD)-deficiency were originally created to establish the neurobiological plausibility of this association. A large body of experimental work demonstrates the developmental absence of vitamin D changes the way the brain develops and leads to behaviors in adults that may be of relevance to schizophrenia [4].

The purpose of this review is to summarize the clinical epidemiology literature linking both developmental and adult vitamin D levels with schizophrenia and critically evaluate mechanistic studies in animals that examine the genomic, non-genomic, and epigenetic actions of this neurosteroid in the brain, and in the production of phenotypes relevant to schizophrenia.

\section{The vitamin D receptor and vitamin D metabolic enzymes are present in the brain}

Vitamin $\mathrm{D}_{3}$ (cholecalciferol) is produced from 7dehydrocholesterol in the skin upon ultraviolet $\mathrm{B}$ radiation [5]. Cholecalciferol is also present in a small number of 
foods and can be obtained by supplementation. Cholecalciferol is hydroxylated to 25-hydroxy vitamin $\mathrm{D}_{3}$ (25OHD), the major circulating form in the blood, which is then converted into the active hormone, 1,25-dihydroxyvitamin $\mathrm{D}\left(1,25(\mathrm{OH})_{2} \mathrm{D}\right)$. $25 \mathrm{OHD}$ and $1,25(\mathrm{OH})_{2} \mathrm{D}$ can both cross the blood brain barrier [6, 7]. Early immunohistochemistry studies first demonstrated the cellular and subcellular localization of the vitamin D receptor (VDR) and vitamin D metabolizing enzymes in human [8,9] and rodent brain [8, 10-19].

An exponential growth in high-throughput sequencing technologies has allowed researchers to assess the relative abundance, known isoforms and splice variants of many important genes. As such, the VDR and the major enzymes responsible for the synthesis and metabolism of vitamin D (cytochrome P450 family members CYP27B1 and CYP24A1) in adult human tissues can be accessed using data from the Genotype-tissue expression (GTEx project) [20]. In the GTEx portal, the expression of the VDR is shown in all 11 human brain regions examined including cerebral cortex, cerebellum, amygdala, anterior cingulate cortex, caudate (basal ganglia), hippocampus, hypothalamus, nucleus accumbens (basal ganglia), putamen (basal ganglia), C-1 spinal cord, and pituitary gland. However, the abundance of VDR is relatively low compared to classic VDR organs such as the gut and kidney. Within the brain, the hypothalamus had the greatest abundance. In organs of high VDR abundance anywhere between 3 and 5 isoforms exist whereas the brain contains the single isoform. A number of single nucleotide polymorphism (SNP) variants are associated with VDR's expression and splicing in tissue such as testis and skin, but not in the brain. Immunohistochemistry studies confirm the VDR is present in developing [9, 17] and adult $[12,15,16]$ animal brains with VDR expression in the midbrain being prominently studied [9]. This has recently also been confirmed via single cell sequencing from developing mouse and human midbrains [21].

In respect to vitamin D's synthetic and metabolic enzymes, the abundance of CYP27B1 is also low in the brain as it is in most other organs apart from kidney. In the brain CYP27B1 levels are most prominent in cerebral cortex and the limbic regions of the caudate putamen and nucleus accumbens. CYP27B1 has seven isoforms with four isoforms detected in kidney and colon, five isoforms in testis, and one in the brain. No correlations between gene variants at the SNP level with enzyme expression or splicing have been reported in the brain. When considering CYP24A1, again expression is low in most organs including brain. The kidney was the only organ shown to contain relatively high levels. CYP24A1 has six isoforms, five of which are present in the kidney, two to four isoforms in other tissue such as bladder and skin, and two isoforms in the brain. Many SNPs are detected in regions likely to be promoter sites indicating they may affect transcription. Indeed such SNPs are associated with CYP24A1 expression in the amygdala, anterior cingulate cortex, cortex, frontal cortex, and nucleus accumbens.

The Allen brain atlas largely confirms that the abundance of VDR and vitamin D-related enzymes is low in human and adult mouse brain and even lower in developing mouse brain [22]. CYP27B1 and CYP24A1 data in the developing mouse brain were not reported in Allen brain atlas.

\section{Developmental vitamin D deficiency and schizophrenia}

Low maternal vitamin $\mathrm{D}$ was proposed as a risk factor for schizophrenia almost two decades ago [1]. This hypothesis was prompted by early ecological epidemiological studies that identified that rates of schizophrenia were higher in those: (1) born in winter and spring [23], (2) who live at high latitudes [24], (3) who were raised in urban settings in early life [25-28]. Vitamin D deficiency is a parsimonious candidate that may underlie these observations - as they all correlate with reduced sunlight exposure and thus a higher prevalence of vitamin D deficiency [29]. A separate observation that the offspring of migrants with dark skin who migrate to cold climates have an increased risk of schizophrenia may also be due to low vitamin D during gestation and early life as dark skin requires greater sunlight exposure to make adequate levels of the vitamin D prehormone [30].

These convergent clues led to the hypothesis that maternal vitamin D deficiency may be a risk-modifying factor for schizophrenia. However, schizophrenia is a low prevalence disorder of adult onset. Therefore, in order to test this hypothesis a sample repository that was both sufficiently large and also possessed samples stored for a sufficiently long time to allow a diagnosis of schizophrenia to be made was required. The Danish Biobank Register based on record linkage between the Danish Psychiatric Central Register and the Danish Civil Registration System have collected and stored neonatal blood spots since 1981 making it an ideal sample source [31, 32].

The first Danish case-control study using these neonatal dried blood spots $(N=868)$ found a significant association between low neonatal vitamin $\mathrm{D}$ status and subsequent risk of developing schizophrenia (lowest versus reference [fourth] quintile incidence rate ratio $(\mathrm{IRR})=2.1 ; 95 \% \mathrm{CI}$ 1.3-3.5) [2]. A second larger Danish case-control study $(N=2602)$ replicated this association between neonatal vitamin D deficiency with an increased risk of schizophrenia (IRR $=1.44,95 \%$ CI: 1.12-1.85) [3]. 


\section{Could maternal vitamin D supplementation prevent schizophrenia in offspring?}

A Finish birth cohort study found that the absence of vitamin D supplements during the first year of life was associated with an increased risk of schizophrenia in male infants [33]. However, randomized clinical trials to examine the effects of maternal vitamin D supplementation on schizophrenia incidence in adult offspring will, in all likelihood, never be conducted. First, there is no evidence to suggest that increasing 25OHD concentration in those sufficient in vitamin D will influence the health of the offspring (indeed, this strategy may be associated with adverse events). Second, it is not ethical to screen pregnant women for vitamin D deficiency and then randomize this sample to placebo or vitamin D supplementation. Finally, it is not feasible to follow up large mother-offspring samples for 20-30 years in order to examine the risk of schizophrenia. However large-scale maternal supplementation trials with vitamin D are underway for a variety of health outcomes [34] and it will be interesting to see in the future whether such interventions led to a reduction in schizophrenia or more early onset psychiatric disorders such as attention deficit hyperactivity disorder or autism [35-37].

\section{Vitamin D levels in patients with schizophrenia}

Overall, the prevalence of vitamin D deficiency in the general population is high $(37.6 \%$ based on review of worldwide data [38]). A systematic review and metaanalysis published 6 years ago found that the pooled prevalence of vitamin D deficiency in people with schizophrenia was 65\% [39]. A very recent systematic review confirmed an overall $70 \%$ prevalence of vitamin D deficiency in people with schizophrenia [40]. We have updated this review (our methods, details of the included studies, forest plots and additional references, and a discussion of the following data can be found in the Supplementary Data). In summary, we identified 43 studies with data related to the association between schizophrenia and vitamin D status (Supplementary Tables 1 and 2). We included 22 studies that provided sufficient data to analyze either standard mean differences (SMD) or odds ratios (OR) in both patients with schizophrenia and controls (Supplementary Fig. 1). With respect to continuous data, based on 15 studies, the SMD was -1.11 (95\% CI $[-2.03,-0.19]$, $p=0.02)$. However, high heterogeneity was observed $\left(I^{2}=\right.$ $99.1 \%, Q(\mathrm{df}=14)=174.04, p<0.0001)$ (Supplementary Fig. 2). We identified nine studies reporting OR for vitamin D deficiency (at least $<50 \mathrm{nmol} / \mathrm{l}$ ) in patients with schizophrenia. The pooled OR was 2.49 (95\% CI [1.17, 5.29], $p=0.018)$, with again high heterogeneity $\left(I^{2}=83.3 \%, Q\right.$ $(\mathrm{df}=8)=44.06, p<0.0001)$. A funnel plot showed no publication bias $(p=0.72)$ (Supplementary Fig. 3). As serum 25OHD levels are also known to be associated with latitude [24], we conducted a meta-regression analysis which showed latitude is not a moderator contributing to the heterogeneity of the meta-analysis (Supplementary Fig. $2 \mathrm{~B}, \quad \mathrm{QM}(\mathrm{df}=1)=2.3100$, regression coefficient $=0.0208, p=0.1285$ ). This is consistent with a previous meta-analysis [39].

With respect to continuous data from the patients with first-episode psychosis (FEP), based on seven studies, the SMD was $(-0.29,95 \%$ CI $[-0.65,0.07], p=0.11)$. Again, high heterogeneity was observed $\left(I^{2}=75.49 \%\right.$, $Q(\mathrm{df}=6)=21.89, p<0.0013)$ (Supplementary Fig. 4). We identified five studies reporting OR for vitamin D deficiency (at least $<50 \mathrm{nmol} / \mathrm{l}$ ) in FEP patients. The pooled OR was 3.78 (95\% CI [2.40, 5.94], $p<0.0001)$. No heterogeneity was detected $\left(I^{2}=0 \%, Q(\mathrm{df}=4)=3.01, p=0.56\right)$ (Supplementary Fig. 5). The findings provide robust evidence confirming earlier smaller meta-analyses $[39,41]$ that those with schizophrenia have an increased risk of vitamin D deficiency. However this finding is also consistent with the finding that poor health in general (mental or physical disorders) can lead to vitamin D deficiency mediated by poor diet, reduced physical activity and changes to behavior which are all factors known to increase the risk of vitamin D deficiency [42].

\section{Vitamin D supplementation in patients with schizophrenia}

In keeping with the poor general health status of patients, osteoporosis is highly prevalent $(\sim 52 \%)$ in patients with schizophrenia [43]. As vitamin D supplementation is the recommended treatment for osteoporosis [44], there exists the opportunity to assess whether vitamin D also affects schizophrenia symptomology. To date, three randomized, double-blind, placebo-controlled clinical trials of vitamin D supplementation either in conjunction with probiotics or maintenance antipsychotic treatment have been conducted. One study showed that vitamin D supplementation $(50,000$ IU vitamin $\mathrm{D} /$ week for 12 weeks) improved positive and negative syndrome scale scores and metabolic profiles including reduction in fasting plasma glucose, and cholesterol levels [45]. The other two clinical trials of vitamin D supplementation $(300,000 \mathrm{IU}$ intramuscular injection twice within 3 months [46], or 14,000 IU oral drops per week for 8 weeks) in patients maintaining antipsychotic treatment did not find any significant improvement in symptoms. Other small open-labeled studies also show inconsistent outcomes. One study had shown that 12 months of vitamin D supplementation in schizophrenic patients without hospitalization is associated with lower depressive symptoms and lower rates of current anxiety [47], whereas earlier studies 
using either 2000 IU orally daily for 8 weeks [48] or low dose dietary (ergocalciferol 400 IU daily for 7 months [49]) did not observe any improvement in symptoms (Supplementary Table 3). So until the results from large-scale, randomized, doubled-blinded placebo-controlled trials intentionally designed to assess the therapeutic effects of vitamin $\mathrm{D}$ in patients with schizophrenia such as the DFEND [50] trial are known, at this stage vitamin D supplementation should be recommended for the prevention of osteoporosis, but not the treatment of schizophrenia symptoms.

\section{Is developmental vitamin $\mathrm{D}$ deficiency a biologically plausible risk factor for schizophrenia?}

\section{DVD deficiency retards brain development in animal models}

In line with its pro-differentiation, anti-proliferation, and anti-apoptosis properties, the absence of vitamin D during gestation delays development with more cells proliferating and less being eliminated in the DVD-deficient rat brain $[51,52]$. Prolonged cell division also correlated with alterations in the expression of cell cycle-regulating genes including cyclin-dependent kinase p21 and p27 as well as cyclin D1 [51]. Neuroprogenitor cells isolated from ventricular zone of DVD-deficient neonates also exhibit enhanced proliferation [53]. Increased cellular proliferation correlates with abnormal brain structure with larger lateral ventricles and a distortion in brain shape [52]. Consistent with these findings, in CYP27B1 knockout mice (this animal cannot produce the active form of vitamin D) neuronal proliferation is also increased in dentate gyrus [54]. In vitro studies provide further support for the anti-proliferating role of vitamin D in developing brain as application of $1,25(\mathrm{OH})$ ${ }_{2} \mathrm{D}$ to rat hippocampal explants inhibited cell division and promoted neurite outgrowth [55]. However, DVD deficiency in the mouse produces a very different developmental brain phenotype with reduced lateral ventricles at embryonic day (E) 17.5 [56, 57]. Whether there are opposite effects on proliferation in the mouse within the DVDdeficient mouse brain remains unknown. However in certain circumstances the addition of vitamin D can also induce proliferation in the brain. Myelination is considered a potential late maturational event that may be abnormal in patients with schizophrenia [58]. When adult rats are chemically demyelinated, oral cholecalciferol supplementation $(5000 \mathrm{IU} / \mathrm{kg} / \mathrm{day})$ promotes the proliferation and differentiation of neural stem cells in the subventricular zone which migrate into the corpus callosum, differentiate into oligodendrocytes and produce myelin basic protein [59].

The effect of DVD-deficiency on differentiation in rat brain may also be due in part to its known regulation of certain neurotrophic factors critical for neuron maturation [60-65]. DVD deficiency reduces nerve growth factor (NGF), glial-derived neurotrophic factor (GDNF), and the nonselective neurotrophic receptor $\mathrm{p} 75^{\mathrm{NTR}}$ in neonatal rat brains $[52,66]$. Brain-derived neurotrophic factor was also reduced in another study but the direction of this finding was dependent on embryonic age [56]. As these trophic factors are well-known to increase neurite outgrowth and dendritic arbor formation [67], it is highly likely their reduction in a DVD-deficient brain may impair early brain connectivity.

\section{DVD deficiency alters DA ontogeny}

The VDR is prominently expressed in DA neurons within the human substantia nigra $[8,9]$. There are many studies of the neuroprotective actions of vitamin D on DA neurons in animal models of Parkinson's disease [68-77]. Many of the proposed protective actions of vitamin $\mathrm{D}$ in adult DA neurons in these studies are also relevant to developing DA neurons. The evidence compiled from the last 20 years supports the hypothesis that vitamin D plays an important role in DA neuron development. The majority of DA neurons are born within the first trimester in a human foetus $[78,79]$. In rodents, virtually all DA neurons are born in the first 14 days of gestation which is roughly equivalent to the first trimester in humans [80]. The capacity for vitamin D signaling emerges progressively in the developing mesencephalon along with DA neuron maturation [9]. Between E12 and E15, when the majority of DA neurons are born in rodents [80], DVD deficiency was shown to reduce the expression of DA neuron specification factor Nurr1 and the rate-limiting enzyme in DA synthesis tyrosine hydroxylase (TH) in rat mesencephalon [81, 82]. The $\mathrm{N}$-cadherin signaling pathway could be a possible mediator in the regulation of DA neuron differentiation [83]. During DA neuron maturation, a reduction of $\mathrm{TH}$ protein is also observed in substantia nigra of DVD-deficient mouse embryos at E17.5 [56]. In neonatal rats, DVD deficiency alters DA neurotransmitter turnover, consistent with the reduction in related catabolic enzymes such as catechol-Omethyltransferase (COMT) [84-86]. DVD deficiency reduces a major co-receptor for GDNF c-Ret [66]. The effects of vitamin D on all these aspects of DA neuron differentiation and metabolism has been studied in detail in VDR-overexpressing SH-SY5Y neuroblastoma cells and has largely been shown to reverse these deficits. Importantly, the direct genomic regulation of several factors crucial to DA neuron maturation and DA turnover has now been demonstrated in these cells $[66,83,86]$. Alterations in other neurotransmitters have also been reported in DVDdeficient brains such as glutamine, serotonin, and noradrenalin [85]. 
Vitamin D deficiency interacts with well-known epidemiologically validated risk factors for schizophrenia

Epidemiological and translational studies show that prenatal infection increases the risk of developing schizophrenia [87]. Vitamin D is an immune regulator [88]. Therefore, it is interesting to note that placentas from DVD-deficient rat dams produce greater amounts of the inflammatory cytokines IL-6 and IL-1 $\beta$ in response to viral stimulation [89].

Obstetric complications are a well-known risk factor for schizophrenia and the placenta has been considered to be a major mediator for this risk. A recent study revealed that placenta is the central organ mediating the interaction between genetic risk variance and prenatal environmental complications increasing the risk of developing schizophrenia [90]. DVD deficiency in mice also reduces placental weight and expression of genes responsible for placental vascular growth [91].

Glucocorticoids play a critical role in early brain development. Abnormalities in glucocorticoid production in response to maternal stress response have also been closely linked to schizophrenia [92]. DVD deficiency in both rat and mouse increase maternal serum glucocorticoid levels [91, 93]. Consistently, a prolonged vitamin D deficiency during gestation and lactation in rodents alters genes involved in glucocorticoid pathways. For instance 11 betahydroxysteroid dehydrogenase type II (Hsd 11b2) (a major enzyme that inactivates glucocorticoids) is reduced by DVD deficiency at postnatal day 1 in rat and at embryonic 14.5 in mouse [91, 94]. DVD deficiency also reduces glucocorticoid receptor (mineralocorticoid receptor, nuclear receptor subfamily 3 group $\mathrm{C}$ member $2, \mathrm{Nr} 3 \mathrm{c} 2$ ) expression and increases $T s c 22 d$ which is a post-receptor mediator of glucocorticoid action in postnatal rat brain and embryonic mouse brain [91, 94].

\section{DVD deficiency alters postnatal and adult brain function and behavior}

When DVD deficiency is maintained postnatally in rats, offspring have alterations in maternal pup interactions, ultrasonic vocalizations, stereotyped repetitive behavior, delayed motor development, and impaired motor control [94-96]. Adolescent DVD-deficient animals exhibit impaired reciprocal social interaction [95]. As adults, DVDdeficient rats display numerous behavioral phenotypes of relevance to schizophrenia (see summary Fig. 1). As adults, DVD-deficient rats have increased spontaneous locomotion [97], baseline cognitive abnormalities in domains of attention $[98,99]$, and behavioral sensitivity to psychomimetics such as the NMDA antagonist MK801 [100-102] and the DA releasing agent amphetamine [103]. DVD deficiency also alters hippocampal long-term potentiation (LTP), a neurobiological correlate of learning and memory [104] and impaired learning ability [105]. Whilst displaying some cognitive abnormalities, DVD-deficient mice, however, have far fewer behavioral phenotypes of interest to schizophrenia [57, 106, 107] again suggesting important differences between the species in the role of vitamin D and brain.

With regards to brain structure and function, DVDdeficient adult rats have enlarged lateral ventricles $[52,108]$ and also altered signaling pathways related to calciumbinding proteins and mitochondrial function [109]. DVDdeficient adult rats also have reduced hippocampal neurogenesis [100, 110]. Interestingly, deficits in LTP, altered neurogenesis and NMDA antagonist induced hyperlocomotion are ameliorated by the antipsychotic haloperidol which blocks dopamine receptors 2 (Drd2) [100, 110] suggesting developmentally induced alterations in DA development may persist into adulthood.

\section{DVD deficiency, genomic, and epigenetic mechanisms}

Like other neurosteriods, vitamin D acts genomically to regulate transcription but also has faster non-genomic actions. To exert its genomic actions, $1,25(\mathrm{OH})_{2} \mathrm{D}$ binds to VDR in the cytoplasm, initiating heterodimerization of the liganded VDR with the retinoic acid X receptor (RXR), which translocates to the nucleus. The liganded VDR/RXR protein complex then binds to vitamin $\mathrm{D}$ responsive elements within regulatory regions of target genes. Finally, corepressors are released and coactivators recruited to promote gene expression. In general, the presence of vitamin D stimulates expression of targets [83, 111, 112]. Its absence leads to reduced expression of these same genes in brain $[56,66,83,84,86]$. Those genes include COMT and c-Ret proto-oncogene [66, 86, 112], as well as L-type voltage gated calcium channels (L-VGCCs) pore forming unit Cav1.2 (coded by CACNA1C) [113, 114]. Variants in these genes have been frequently linked with schizophrenia [115-117].

VDR's genomic actions are accompanied by epigenetic processes including histone modification. Histone acetylation is a fundamental step in allowing transcription factor access to DNA. Histones are acetylated by histone acetyltransferase (HAT). Coactivators of the VDR such as p160 or p300/CBP, all have HAT activity to promote transcription in the presence of $1,25(\mathrm{OH})_{2} \mathrm{D}$ [118-121]. Conversely, histone deacetylation by histone deacetylase enzymes (HDACs) reverses this process to decrease gene transcription. In the absence of vitamin D, corepressors of VDR either have HDAC activity themselves such as protein ALIEN [122], or interact with HDACs such as the nuclear receptor corepressor and the silencing mediator of retinoid and thyroid hormone receptor to inhibit transcription [123-125]. 


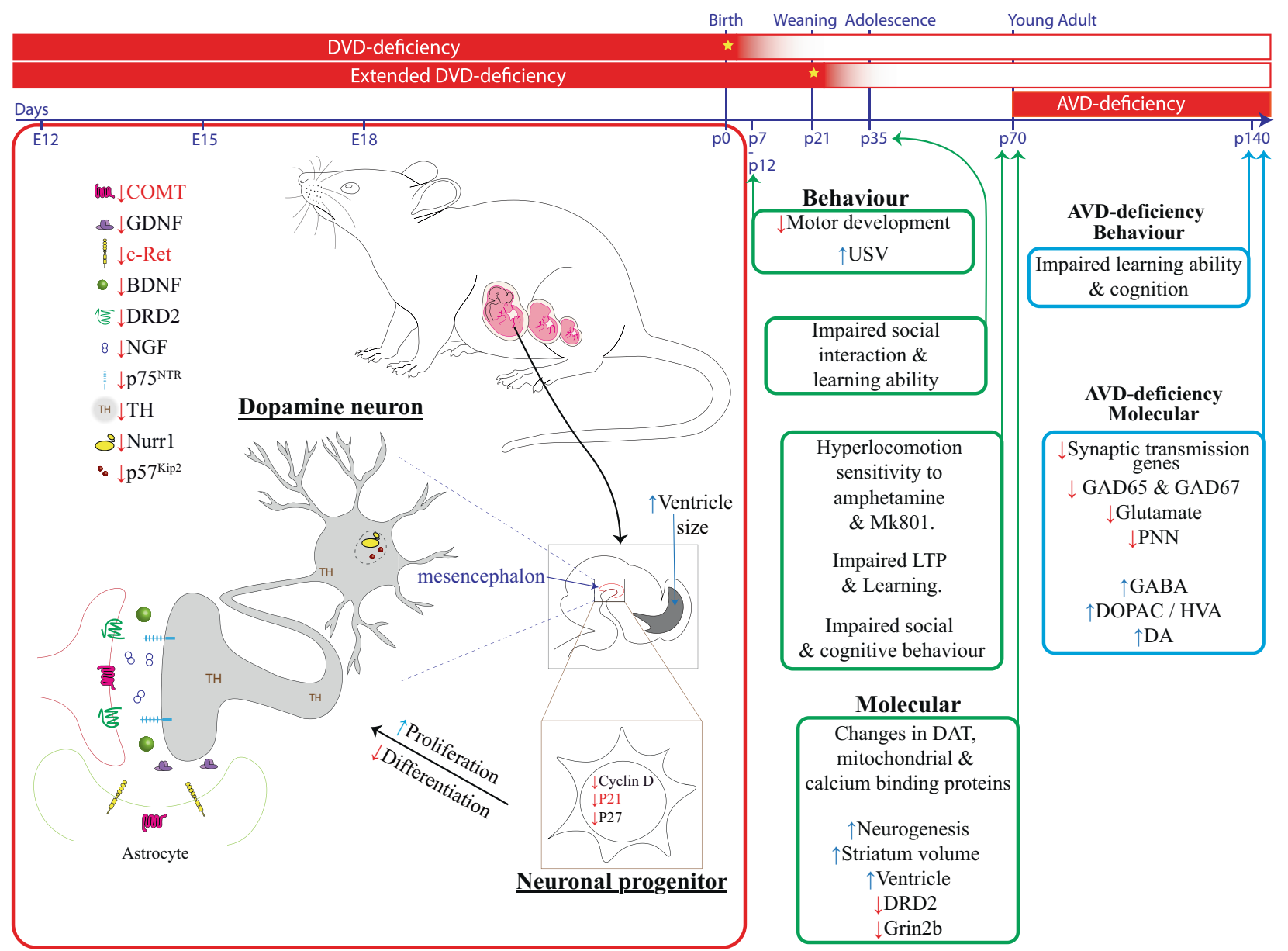

Developmental

Fig. 1 Timelines of vitamin $D$ deficiency in preclinical studies is depicted along with reported alterations. Red boxes depict the period of vitamin D deficiency. Yellow star indicates the time when the normal vitamin D containing diets were reintroduced. Preclinical studies of developmental vitamin D (DVD) deficiency show extensive alterations to developing dopamine (DA) neurons, neuronal differentiation, alterations to brain structure and behavioral phenotypes of interest to schizophrenia (green boxes). DVD deficiency reduces many DA-related genes. Multiple vitamin D response elements (VDREs) have been predicted in the promoters of all genes listed (in silico in black text) using the online software (MoloTool, Transcription Factor Motif Location Toolbox Version 11) [144]. Those genes listed in red have been functionally validated, i.e directly regulated by liganded VDR interacting with VDREs within their promoters. Preclinical studies of adult vitamin D (AVD) deficiency show a number of

An interesting recent study from Broekema et al. using a reporter assay show that upon ligand binding to the VDR, 38 corepressors are released and 86 coactivators increase their binding to the VDR [126]. Many of these molecules are shared coregulators for other nuclear receptors and are found in the brain [127]. These coregulator interactions with the VDR are tissue, region, time, and gene specific. The exact co-regulation mechanisms activated or suppressed in the developing or adult brain in the absence of vitamin D remain to be established. neurotransmitter alterations and impaired cognition (blue boxes). DVD deficiency developmental vitamin D deficiency, AVD deficiency adult vitamin D deficiency, E12-E18 embryonic days 12-18, p0-140 postnatal days $0-140$, COMT Catechol-O-methyltransferase, GDNF glia-derived neurotrophic factor, cRET ret proto-oncogene, DRD2 dopamine receptor D2, NGF nerve growth factor, BDNF brain-derived neurotrophic factor, p75NTR neurotrophin receptor P75, TH tyrosine hydroxylase, Nurr1 nuclear receptor-related 1, p57kip2 cyclindependent kinase inhibitor $1 \mathrm{C}$, p21 cyclin-dependent kinase inhibitor 1A, p27 cyclin-dependent kinase inhibitor 1B, USV ultrasonic vocalization, LTP long-term potentiation, DAT dopamine transporter, Grin2b glutamate ionotropic receptor NMDA type subunit 2B, GAD glutamate decarboxylase, PNN perineuronal net, GABA gammaaminobutyric acid, DOPAC 3,4-Dihydroxyphenylacetic acid, HVA homovanillic acid (Color figure online).

\section{Non-genomic mechanisms of vitamin D on the developing brain?}

Non-genomic actions occur in time frame of seconds to a few minutes and are obviously independent of transcription. One of the most prominent non-genomic actions of vitamin $\mathrm{D}$ is to rapidly enhance L-VGCCs activity in bone, cartilage, cardiac, and skeletal muscle [128-131]. This has only very recently been confirmed in the developing brain. Gooch et al. have now shown $1,25(\mathrm{OH})_{2} \mathrm{D}$ rapidly enhances 
activity-dependent calcium influx via -LVGCC in a small population of neurons in the P10 mouse prefrontal cortex [132]. Considering the aforementioned genomic effects of vitamin D on LVGCC expression in developing neurons $[113,133]$, we speculate that in the presence of vitamin D deficiency, L-VGCCs properties are transiently alteredthis may be a key pathway mediating the impact of DVD deficiency on brain development. Indeed the developmental inactivation LVGCC (deletion of CACNA1C) in mouse forebrain induces behavioral phenotypes of relevance to schizophrenia in adults, including hyperactivity, cognitive impairment, and reduced sociability [134]. Importantly, inactivation L-VGCCs in adult brain in this same study produced no behavioral phenotype of relevance to schizophrenia. The relevance of this potential mechanism to schizophrenia is exemplified by the last major genome-wide association study from the Schizophrenia Working Group of the Psychiatric Genomics Consortium which showed LVGCC subunit variants to be associated with an increased risk for schizophrenia [117].

\section{The impact of adult vitamin D deficiency on brain function}

In contrast to DVD deficiency models where the existing data indicate the development and function of DA systems is primarily affected, AVD deficiency interrupts excitatory and inhibitory neurocircuits and may alter cognitive function. Like DVD deficiency, the impact of AVD deficiency on brain chemistry or behaviors differs across species (rat or mouse).

\section{AVD deficiency and neurocircuits}

AVD deficiency dysregulates the balance of excitatory and inhibitory neurotransmitters differentially in mice and rats. In BALB/c mice AVD deficiency decreases glutamate and glutamine but increases gamma aminobutyric acid (GABA) and glycine levels [135]. In Wistar rats, vitamin D deficiency enhances baseline glutamate and GABA levels but reduces evoked release of both neurotransmitters. Importantly, vitamin D supplementation rescues the shift between unstimulated and evoked GABA release but only partially restores the impaired glutamate release [136]. The imbalance of excitatory and inhibitory neurotransmitters could be associated with the intensified reactive oxygen species production and elevated free calcium levels in terminals. Another possible mechanism for this dysregulation may be the downregulation of perineuronal nets (PNNs) surrounding inhibitory interneurons in AVD-deficient hippocampus [137]. PNNs are a specialized form of the extracellular matrix that contribute substantially to the excitatory/inhibitory balance by maintaining GABAergic interneuron gamma oscillations [138, 139]. In addition, AVD-deficient mice have a disrupted network centered on the right hippocampus with abnormal connectome within 29 nodes, although there is no direct evidence linking these findings to alterations in PNNs [137]. AVD deficiency also increased GABA levels in Sprague Dawley rats as well as altering striatal DA turnover in rats and mice [135, 140]. In keeping with the difference in behavioral phenotypes between AVDand DVD deficiency, AVD-deficient mice have a reduced locomotor response to amphetamine [141].

\section{AVD deficiency and cognitive function}

AVD deficiency induces cognitive impairment in rodent models, though the behavioral outcomes differ between species or strains. AVD deficiency in Sprague Dawley rats increases impulsivity on the 5-choice serial reaction task [140]. AVD-deficient Wistar or Fischer rats also have impairments in hippocampal-dependent memory $[142,143]$. AVD-deficient BALB/c mice also have impairments in attention and hippocampal-dependent learning [144].

Overall, there is a growing body of evidence to suggest that AVD deficiency can result in subtle changes in brain neurochemistry and selected behavioral readouts consistent with impaired cognitive function. It is feasible that AVD deficiency may influence the course of preexisting illnesses. For example, an RCT of vitamin D supplementation in patients with Parkinson's disease found the expected decline over time in the placebo group (in keeping with progression of this neurodegenerative disorder). In contrast, the active vitamin D group preserved neurological function [145]. Thus, the absence of the expected concentration of $1,25(\mathrm{OH})_{2} \mathrm{D}$ may accelerate progression of a prior disorder [146]. It remains to be seen if these factors also influence recovery or progression of psychiatric disorders.

\section{What has the last 20 years research produced?}

The last 20 years has seen neonatal vitamin D deficiency emerge as a plausible candidate risk factor for schizophrenia. Earlier studies examining environmental phenomena such as season of birth as proxy markers for DVD deficiency have given way to direct analytical epidemiological studies [2,3]. Such studies now await replication in other tissue repositories. The last 20 years have produced substantial preclinical work establishing vitamin D as an essential neurodevelopmental steroid. Preclinical studies have provided robust evidence that DVD deficiency adversely affects brain structure, delays brain cell maturation, and produces neurochemical and behavioral phenotypes of relevance to schizophrenia. In particular, there has been a concerted effort in preclinical studies suggesting that alterations in vitamin D status affect the ontogeny and 
survival of DA neurons. Altered DA neuron ontogeny is emerging as a plausible convergent mechanism in broader risk factor epidemiology in schizophrenia [147]. Of relevance here are recent studies showing a systemic injection of $1,25(\mathrm{OH})_{2} \mathrm{D}$ in pregnant animals at early developmental stages not only blocked maternal inflammation induced behavioral phenotypes related to subcortical hyperdopaminergia but also normalized early aspects of DA neuron gene expression and early DA neuron migration [111, 148].

With respect to vitamin D levels in patients, systematic reviews have convincingly shown that people with schizophrenia are at increased risk of vitamin D deficiency. Whilst there is no convincing evidence that low vitamin D levels adversely affects adult brain health from a clinical perspective, vitamin D deficiency in this patient group should still be taken seriously. Low vitamin D levels are also associated with general physical health problems, including adverse cardiovascular outcomes [149] and so may potentially compound the poor health status associated with psychotic disorders and their treatment [150]. This issue should therefore be incorporated in general dietary advice for patients with schizophrenia.

In preclinical studies, AVD deficiency appears to have a subtle but consistent impact on learning and memory. Although there is some evidence that AVD deficiency induces alterations in the balance of excitatory/inhibitory neurotransmitters [135] and/or in PNN density [137] any underlying mechanism linking AVD deficiency and altered cognition remains elusive. It is feasible that vitamin D deficiency may contribute to poorer clinical outcomes in those with preexisting brain disorders [151]. Thus, ongoing research into these mechanisms are warranted.

\section{Future directions}

\section{Is there a critical window of vitamin D deficiency during development?}

The existing evidence base connecting DVD deficiency and schizophrenia is limited to newborns. However, it is feasible that low serum vitamin $\mathrm{D}$ during childhood and puberty could also affect brain development. For instance, absence of vitamin D supplementation during the first year of life also correlates with increased incidence of schizophrenia [33]. Additionally, dark skinned (people with dark skin require greater sunlight exposure to make adequate levels of vitamin D [152]) migrants to the Netherlands (children who immigrated at age 3-17 years) have increased risk of later psychotic disorders [30]. This suggests that postnatal vitamin D deficiency may also adversely affect brain development. This hypothesis is supported by limited evidence from preclinical studies. When vitamin D deficiency is extended to weaning (postnatal day 21, extended DVD deficiency), the ventriculomegaly seen in DVD-deficient neonates persists to adulthood [108]. Vitamin D deficiency during puberty in a rat also decreases glutamate and GABA uptake by reducing the expression of glutamate (EAAC-1) and GABA (GAT-3) transporters [153]. However, a recent study purposely designed to examine negative and cognitive symptom phenotypes in response to varying pre- and postnatal windows of vitamin $\mathrm{D}$ deficiency failed to show any exacerbation of behavioral phenotypes with prolonged DVD deficiency. Instead, all pre- and postnatal windows of DVD deficiency impaired novel object recognition [154]. Clearly, further preclinical studies are needed to examine the effects of postnatal vitamin D deficiency on brain structure and function. Until then, the importance of postnatal vitamin D deficiency to schizophrenia risk remains unknown.

\section{How does DVD deficiency affect gene regulation in developing brains?}

In terms of understanding vitamin D's role in gene regulation in developing and adult brains, there is still much we do not understand. Some studies have provided evidence for a direct genomic interaction between the liganded VDR with promoters of known DA-related gene targets in developing brains $[66,86]$. However, it is also highly likely that vitamin D's well-described epigenetic control of transcription in cancer cells via histone acetylation, promoter methylation or via miRNAs is also prominent in brain though this remains virtually unexplored. Given clear and consistent effects of DVD- and AVD deficiency on the expression of certain genes highly relevant to brain development and function such research should now be conducted.

\section{Conclusion}

Neonatal vitamin D deficiency is associated with an increased risk of schizophrenia. The ease of manipulating this dietary factor has facilitated a vast amount of preclinical studies in rat and mouse both in developing and in adult animals. Animal models were initially examined to establish the biological plausibility of this risk relationship. However, the real power of such studies is their ability to uncover potentially vulnerable or disease causative pathways. Whilst there are likely to be many upstream causative agents and pathways to schizophrenia the consistent findings from DVD deficiency showing abnormalities in how DA neurons develop and function in adult brains and the links emerging between GABA neurons and cognitive deficits in AVDdeficient animals is tantalizing as these are highly plausible disease causative pathways (see summary Fig. 1). Adequate 
vitamin D levels have long been considered essential for bone health. The last 20 years of data have revealed that vitamin $\mathrm{D}$ deficiency also impacts on brain development and function.

Acknowledgements Funding was received from the National Health and Medical Research Council grants 1141699 (DWE) and 1099709 (JJMG). JJMG is supported by the Danish National Research Foundation (Niels Bohr Professorship). All authors are employed by The Queensland Centre for Mental Health Research which receives core funding from the Queensland Health. Suzy Alexander is thanked for creating the summary figure.

\section{Compliance with ethical standards}

Conflict of interest The authors declare that they have no conflict of interest.

Publisher's note Springer Nature remains neutral with regard to jurisdictional claims in published maps and institutional affiliations.

Open Access This article is licensed under a Creative Commons Attribution 4.0 International License, which permits use, sharing, adaptation, distribution and reproduction in any medium or format, as long as you give appropriate credit to the original author(s) and the source, provide a link to the Creative Commons license, and indicate if changes were made. The images or other third party material in this article are included in the article's Creative Commons license, unless indicated otherwise in a credit line to the material. If material is not included in the article's Creative Commons license and your intended use is not permitted by statutory regulation or exceeds the permitted use, you will need to obtain permission directly from the copyright holder. To view a copy of this license, visit http://creativecommons. org/licenses/by/4.0/.

\section{References}

1. McGrath J. Hypothesis: is low prenatal vitamin D a riskmodifying factor for schizophrenia? Schizophr Res. 1999;40:173-7.

2. McGrath JJ, Eyles DW, Pedersen CB, Anderson C, Ko P, Burne $\mathrm{TH}$, et al. Neonatal vitamin D status and risk of schizophrenia: a population-based case-control study. Arch Gen Psychiatry. 2010;67:889-94.

3. Eyles DW, Trzaskowski M, Vinkhuyzen AAE, Mattheisen M, Meier S, Gooch $\mathrm{H}$, et al. The association between neonatal vitamin D status and risk of schizophrenia. Sci Rep. 2018;8:17692.

4. Cui X, Gooch H, Petty A, McGrath JJ, Eyles D. Vitamin D and the brain: genomic and non-genomic actions. Mol Cell Endocrinol. 2017;453:131-43.

5. Holick MF, Matsuoka LY, Wortsman J. Regular use of sunscreen on vitamin D levels. Arch Dermatol. 1995;131:1337-9.

6. Pardridge WM, Sakiyama R, Coty WA. Restricted transport of vitamin $\mathrm{D}$ and A derivatives through the rat blood-brain barrier. $\mathrm{J}$ Neurochem. 1985;44:1138-41.

7. Spach KM, Hayes CE. Vitamin $\mathrm{D}_{3}$ confers protection from autoimmune encephalomyelitis only in female mice. J Immunol. 2005; 175:4119-26.

8. Eyles DW, Smith S, Kinobe R, Hewison M, McGrath JJ. Distribution of the vitamin $\mathrm{D}$ receptor and 1 alpha-hydroxylase in human brain. J Chem Neuroanat. 2005;29:21-30.
9. Cui X, Pelekanos M, Liu PY, Burne TH, McGrath JJ, Eyles DW. The vitamin D receptor in dopamine neurons; its presence in human substantia nigra and its ontogenesis in rat midbrain. Neuroscience. 2013;236:77-87.

10. Naveilhan P, Neveu I, Baudet C, Ohyama KY, Brachet P, Wion D. Expression of $25(\mathrm{OH})$ vitamin $\mathrm{D}_{3}$ 24-hydroxylase gene in glial cells. Neuroreport. 1993;5:255-7.

11. Fu GK, Lin D, Zhang MY, Bikle DD, Shackleton CH, Miller WL, et al. Cloning of human 25-hydroxyvitamin D-1 alphahydroxylase and mutations causing vitamin D-dependent rickets type 1. Mol Endocrinol. 1997;11:1961-70.

12. Smolders J, Schuurman KG, van Strien ME, Melief J, Hendrickx D, Hol EM, et al. Expression of vitamin D receptor and metabolizing enzymes in multiple sclerosis-affected brain tissue. $\mathbf{J}$ Neuropathol Exp Neurol. 2013;72:91-105.

13. Boontanrart M, Hall SD, Spanier JA, Hayes CE, Olson JK. Vitamin $D_{3}$ alters microglia immune activation by an IL-10 dependent SOCS3 mechanism. J Neuroimmunol. 2016;292:126-36.

14. Landel V, Stephan D, Cui X, Eyles D, Feron F. Differential expression of vitamin D-associated enzymes and receptors in brain cell subtypes. J Steroid Biochem Mol Biol. 2017;177:129-34.

15. Glaser SD, Veenstra TD, Jirikowski GF, Prufer K. Distribution of 1,25-dihydroxyvitamin $\mathrm{D}_{3}$ receptor immunoreactivity in the rat olfactory system. Cell Mol Neurobiol. 1999;19:613-24.

16. Prufer K, Veenstra TD, Jirikowski GF, Kumar R. Distribution of 1,25-dihydroxyvitamin $\mathrm{D}_{3}$ receptor immunoreactivity in the rat brain and spinal cord. J Chem Neuroanat. 1999;16:135-45.

17. Veenstra TD, Prufer K, Koenigsberger C, Brimijoin SW, Grande JP, Kumar R. 1,25-Dihydroxyvitamin $\mathrm{D}_{3}$ receptors in the central nervous system of the rat embryo. Brain Res. 1998;804:193-205.

18. Eyles DW, Liu PY, Josh P, Cui X. Intracellular distribution of the vitamin $\mathrm{D}$ receptor in the brain: comparison with classic target tissues and redistribution with development. Neuroscience. 2014;268:1-9.

19. Stumpf WE, O'Brien LP. Autoradiographic studies with $3 \mathrm{H} 1,25$ dihydroxyvitamin $\mathrm{D}_{3}$ in thyroid and associated tissues of the neck region. Histochemistry. 1987;87:53-8.

20. Carithers LJ, Ardlie K, Barcus M, Branton PA, Britton A, Buia SA, et al. A novel approach to high-quality postmortem tissue procurement: the GTEx project. Biopreserv Biobank. 2015;13:311-9.

21. La Manno G, Gyllborg D, Codeluppi S, Nishimura K, Salto C, Zeisel A, et al. Molecular diversity of midbrain development in mouse, human, and stem. Cells Cell. 2016;167:566-80 e519.

22. Sunkin SM, Ng L, Lau C, Dolbeare T, Gilbert TL, Thompson CL, et al. Allen Brain Atlas: an integrated spatio-temporal portal for exploring the central nervous system. Nucleic Acids Res. 2013;41:D996-1008.

23. Torrey EF, Miller J, Rawlings R, Yolken RH. Seasonality of births in schizophrenia and bipolar disorder: a review of the literature. Schizophr Res. 1997;28:1-38.

24. Saha S, Chant D, McGrath J. Meta-analyses of the incidence and prevalence of schizophrenia: conceptual and methodological issues. Int J Methods Psychiatr Res. 2008;17:55-61.

25. McGrath J, Scott J. Urban birth and risk of schizophrenia: a worrying example of epidemiology where the data are stronger than the hypotheses. Epidemiol Psichiatr Soc. 2006;15:243-6.

26. Marcelis M, Takei N, van Os J. Urbanization and risk for schizophrenia: does the effect operate before or around the time of illness onset? Psychol Med. 1999;29:1197-203.

27. Mortensen PB, Pedersen CB, Westergaard T, Wohlfahrt J, Ewald $\mathrm{H}$, Mors $\mathrm{O}$, et al. Effects of family history and place and season of birth on the risk of schizophrenia. $\mathrm{N}$ Engl $\mathrm{J}$ Med. 1999;340:603-8. 
28. March D, Hatch SL, Morgan C, Kirkbride JB, Bresnahan M, Fearon $\mathrm{P}$, et al. Psychosis and place. Epidemiol Rev. 2008;30:84-100.

29. Holick MF. Environmental factors that influence the cutaneous production of vitamin D. Am J Clin Nutr. 1995;61:638S-45S.

30. Hintzpeter B, Scheidt-Nave C, Muller MJ, Schenk L, Mensink GB. Higher prevalence of vitamin D deficiency is associated with immigrant background among children and adolescents in Germany. J Nutr. 2008;138:1482-90.

31. Pedersen CB. The Danish Civil Registration System. Scand J Public Health. 2011;39:22-5.

32. Pedersen CB, Gotzsche H, Moller JO, Mortensen PB. The Danish Civil Registration System. A cohort of eight million persons. Dan Med Bull. 2006;53:441-9.

33. McGrath J, Saari K, Hakko H, Jokelainen J, Jones P, Jarvelin MR, et al. Vitamin D supplementation during the first year of life and risk of schizophrenia: a Finnish birth cohort study. Schizophr Res. 2004;67:237-45.

34. Wagner CL, McNeil R, Hamilton SA, Winkler J, Rodriguez Cook C, Warner G, et al. A randomized trial of vitamin D supplementation in 2 community health center networks in South Carolina. Am J Obstet Gynecol. 2013;208:137 e131-113.

35. Vinkhuyzen AA, Eyles DW, Burne TH, Blanken LM, Kruithof CJ, Verhulst F, et al. Gestational vitamin D deficiency and autism-related traits: the Generation R Study. Mol Psychiatry. 2016;23:240-6.

36. Vinkhuyzen AAE, Eyles DW, Burne THJ, Blanken LME, Kruithof CJ, Verhulst F, et al. Gestational vitamin D deficiency and autism spectrum disorder. BJPsych Open. 2017;3:85-90.

37. Lee BK, Eyles DW, Magnusson C, Newschaffer CJ, McGrath JJ, Kvaskoff D, et al. Developmental vitamin D and autism spectrum disorders: findings from the Stockholm Youth Cohort. Mol Psychiatry. 2019. https://doi.org/10.1038/s41380-019-0578-y.

38. Hilger J, Friedel A, Herr R, Rausch T, Roos F, Wahl DA, et al. A systematic review of vitamin $\mathrm{D}$ status in populations worldwide. Br J Nutr. 2014;111:23-45.

39. Valipour G, Saneei P, Esmaillzadeh A. Serum vitamin D levels in relation to schizophrenia: a systematic review and metaanalysis of observational studies. J Clin Endocrinol Metab. 2014;99:3863-72.

40. Zhu JL, Luo WW, Cheng X, Li Y, Zhang QZ, Peng WX. Vitamin D deficiency and schizophrenia in adults: a systematic review and meta-analysis of observational studies. Psychiatry Res. 2020;288:112959.

41. Belvederi Murri M, Respino M, Masotti M, Innamorati M, Mondelli V, Pariante C, et al. Vitamin D and psychosis: mini meta-analysis. Schizophr Res. 2013;150:235-9.

42. Momen NC, Plana-Ripoll O, Agerbo E, Benros ME, Borglum $\mathrm{AD}$, Christensen MK, et al. Association between mental disorders and subsequent medical conditions. N Engl J Med. 2020;382:1721-31.

43. Stubbs B, De Hert M, Sepehry AA, Correll CU, Mitchell AJ, Soundy A, et al. A meta-analysis of prevalence estimates and moderators of low bone mass in people with schizophrenia. Acta Psychiatr Scand. 2014;130:470-86.

44. Aspray TJ, Bowring C, Fraser W, Gittoes N, Javaid MK, Macdonald $\mathrm{H}$, et al. National Osteoporosis Society vitamin D guideline summary. Age Ageing. 2014;43:592-5.

45. Ghaderi A, Banafshe HR, Mirhosseini N, Moradi M, Karimi MA, Mehrzad F, et al. Clinical and metabolic response to vitamin D plus probiotic in schizophrenia patients. BMC Psychiatry. 2019;19:77.

46. Sheikhmoonesi F, Zarghami M, Mamashli S, Yazdani Charati J, Hamzehpour R, Fattahi S, et al. Effectiveness of vitamin D supplement therapy in chronic stable schizophrenic male patients: a randomized controlled trial. Iran J Pharm Res. 2016;15:941-50.

47. Fond G, Godin O, Schurhoff F, Berna F, Bulzacka E, Andrianarisoa $\mathrm{M}$, et al. Hypovitaminosis D is associated with depression and anxiety in schizophrenia: Results from the national FACE-SZ cohort. Psychiatry Res. 2018;270:104-10.

48. Thakurathi N, Stock S, Oppenheim CE, Borba CP, Vincenzi B, Seidman LJ, et al. Open-label pilot study on vitamin $\mathrm{D}(3)$ supplementation for antipsychotic-associated metabolic anomalies. Int Clin Psychopharmacol. 2013;28:275-82.

49. Tiangga E, Gowda A, Dent J. Vitamin D deficiency in psychiatric in-patients and treatment with daily supplements of calcium and ergocalciferol. BJPsych Bull. 2008;32:390-3.

50. Gaughran F, Stringer D, Berk M, Smith S, Taylor D, Whiskey E, et al. Vitamin D supplementation compared to placebo in people with First Episode psychosis-Neuroprotection Design (DFEND): a protocol for a randomised, double-blind, placebocontrolled, parallel-group trial. Trials. 2020;21:14.

51. Ko P, Burkert R, McGrath J, Eyles D. Maternal vitamin $\mathrm{D}_{3}$ deprivation and the regulation of apoptosis and cell cycle during rat brain development. Brain Res Dev Brain Res. 2004; 153:61-8.

52. Eyles D, Brown J, Mackay-Sim A, McGrath J, Feron F. Vitamin $\mathrm{D}_{3}$ and brain development. Neuroscience. 2003;118:641-53.

53. Cui X, McGrath JJ, Burne TH, Mackay-Sim A, Eyles DW. Maternal vitamin D depletion alters neurogenesis in the developing rat brain. Int J Dev Neurosci. 2007;25:227-32.

54. Zhu Y, Zhou R, Yang R, Zhang Z, Bai Y, Chang F, et al. Abnormal neurogenesis in the dentate gyrus of adult mice lacking 1,25-dihydroxy vitamin $\mathrm{D}_{3}\left(1,25-(\mathrm{OH}) 2 \mathrm{D}_{3}\right)$. Hippocampus. 2012;22:421-33.

55. Burket R, McGrath J, Eyles D. Vitamin D receptor expression in the embyonic brain. Neurosci Res Commun. 2003;33:67-71.

56. Hawes JE, Tesic D, Whitehouse AJ, Zosky GR, Smith JT, Wyrwoll CS. Maternal vitamin D deficiency alters fetal brain development in the BALB/c mouse. Behav Brain Res. 2015;286:192-200.

57. Harms LR, Cowin G, Eyles DW, Kurniawan ND, McGrath JJ, Burne TH. Neuroanatomy and psychomimetic-induced locomotion in C57BL/6J and 129/X1SvJ mice exposed to developmental vitamin D deficiency. Behav Brain Res. 2012;230:125-31.

58. Maas DA, Valles A, Martens GJM. Oxidative stress, prefrontal cortex hypomyelination and cognitive symptoms in schizophrenia. Transl Psychiatry. 2017;7:e1171.

59. Gomez-Pinedo U, Cuevas JA, Benito-Martin MS, MorenoJimenez L, Esteban-Garcia N, Torre-Fuentes L, et al. Vitamin D increases remyelination by promoting oligodendrocyte lineage differentiation. Brain Behav. 2020;10:e01498.

60. Cornet A, Baudet C, Neveu I, Baron-Van Evercooren A, Brachet P, Naveilhan P. 1,25-Dihydroxyvitamin $D_{3}$ regulates the expression of VDR and NGF gene in Schwann cells in vitro. J Neurosci Res. 1998;53:742-6.

61. Garcion E, Wion-Barbot N, Montero-Menei CN, Berger F, Wion D. New clues about vitamin D functions in the nervous system. Trends Endocrinol Metab. 2002;13:100-5.

62. Naveilhan P, Neveu I, Wion D, Brachet P. 1,25-Dihydroxyvitamin $\mathrm{D}_{3}$, an inducer of glial cell line-derived neurotrophic factor. Neuroreport. 1996;7:2171-5.

63. Neveu I, Naveilhan P, Baudet C, Brachet P, Metsis M. 1,25dihydroxyvitamin $\mathrm{D}_{3}$ regulates NT-3, NT-4 but not BDNF mRNA in astrocytes. Neuroreport. 1994;6:124-6.

64. Neveu I, Naveilhan P, Jehan F, Baudet C, Wion D, De Luca HF, et al. 1,25-dihydroxyvitamin $\mathrm{D}_{3}$ regulates the synthesis of nerve growth factor in primary cultures of glial cells. Brain Res Mol Brain Res. 1994;24:70-6. 
65. Saporito MS, Wilcox HM, Hartpence KC, Lewis ME, Vaught JL, Carswell S. Pharmacological induction of nerve growth factor mRNA in adult rat brain. Exp Neurol. 1993;123:295-302.

66. Pertile RAN, Cui X, Hammond L, Eyles DW. Vitamin D regulation of GDNF/Ret signaling in dopaminergic neurons. FASEB J. 2017;32:819-28.

67. Labelle C, Leclerc N. Exogenous BDNF, NT-3 and NT-4 differentially regulate neurite outgrowth in cultured hippocampal neurons. Brain Res Dev Brain Res. 2000;123:1-11.

68. Wang JY, Wu JN, Cherng TL, Hoffer BJ, Chen HH, Borlongan $\mathrm{CV}$, et al. Vitamin $\mathrm{D}(3)$ attenuates 6-hydroxydopamine-induced neurotoxicity in rats. Brain Res. 2001;904:67-75.

69. Wang L, Evatt ML, Maldonado LG, Perry WR, Ritchie JC, Beecham GW, et al. Vitamin D from different sources is inversely associated with Parkinson disease. Mov Disord. 2015;30:560-6.

70. Calvello R, Cianciulli A, Nicolardi G, De Nuccio F, Giannotti L, Salvatore R, et al. Vitamin D treatment attenuates neuroinflammation and dopaminergic neurodegeneration in an animal model of parkinson's disease, shifting M1 to M2 microglia Responses. J Neuroimmune Pharmacol. 2016;12:327-39.

71. Cass WA, Peters LE, Fletcher AM, Yurek DM. Evoked dopamine overflow is augmented in the striatum of calcitriol treated rats. Neurochem Int. 2012;60:186-91.

72. Cass WA, Peters LE, Fletcher AM, Yurek DM. Calcitriol promotes augmented dopamine release in the lesioned striatum of 6hydroxydopamine treated rats. Neurochem Res. 2014;39: 1467-76.

73. Cass WA, Smith MP, Peters LE. Calcitriol protects against the dopamine- and serotonin-depleting effects of neurotoxic doses of methamphetamine. Ann NY Acad Sci. 2006;1074:261-71.

74. Kim JS, Ryu SY, Yun I, Kim WJ, Lee KS, Park JW, et al. 1alpha,25-Dihydroxyvitamin $\mathrm{D}(3)$ protects dopaminergic neurons in rodent models of parkinson's disease through Inhibition of microglial activation. J Clin Neurol. 2006;2:252-7.

75. Kosakai A, Ito D, Nihei Y, Yamashita S, Okada Y, Takahashi K, et al. Degeneration of mesencephalic dopaminergic neurons in klotho mouse related to vitamin D exposure. Brain Res. 2011;1382:109-17.

76. Orme RP, Bhangal MS, Fricker RA. Calcitriol imparts neuroprotection in vitro to midbrain dopaminergic neurons by upregulating GDNF expression. PLoS ONE. 2013;8:e62040.

77. Sanchez B, Relova JL, Gallego R, Ben-Batalla I, PerezFernandez R. 1,25-Dihydroxyvitamin $\mathrm{D}_{3}$ administration to 6hydroxydopamine-lesioned rats increases glial cell line-derived neurotrophic factor and partially restores tyrosine hydroxylase expression in substantia nigra and striatum. J Neurosci Res. 2009;87:723-32.

78. Freeman TB, Spence MS, Boss BD, Spector DH, Strecker RE, Olanow CW, et al. Development of dopaminergic neurons in the human substantia nigra. Exp Neurol. 1991;113:344-53.

79. Verney C, Zecevic N, Nikolic B, Alvarez C, Berger B. Early evidence of catecholaminergic cell groups in 5- and 6-week-old human embryos using tyrosine hydroxylase and dopamine-betahydroxylase immunocytochemistry. Neurosci Lett. 1991;131: $121-4$.

80. Gates MA, Torres EM, White A, Fricker-Gates RA, Dunnett SB. Re-examining the ontogeny of substantia nigra dopamine neurons. Eur J Neurosci. 2006;23:1384-90.

81. Luan W, Hammond LA, Cotter E, Osborne GW, Alexander SA, Nink V, et al. Developmental vitamin D (DVD) deficiency reduces nurr1 and $\mathrm{TH}$ expression in post-mitotic dopamine neurons in rat mesencephalon. Mol Neurobiol. 2018;55:2443-53.

82. Cui X, Pelekanos M, Burne TH, McGrath JJ, Eyles DW. Maternal vitamin D deficiency alters the expression of genes involved in dopamine specification in the developing rat mesencephalon. Neurosci Lett. 2010;486:220-3.

83. Cui X, Pertile R, Liu P, Eyles DW. Vitamin D regulates tyrosine hydroxylase expression: $\mathrm{N}$-cadherin a possible mediator. Neuroscience. 2015;304:90-100.

84. Kesby JP, Cui XY, Ko P, McGrath JJ, Burne THJ, Eyles DW. Developmental vitamin D deficiency alters dopamine turnover in neonatal rat forebrain. Neurosci Lett. 2009;461:155-8.

85. Kesby JP, Turner KM, Alexander S, Eyles DW, McGrath JJ, Burne THJ. Developmental vitamin D deficiency alters multiple neurotransmitter systems in the neonatal rat brain. Int $\mathrm{J}$ Dev Neurosci. 2017;62:1-7.

86. Pertile RA, Cui X, Eyles DW. Vitamin D signaling and the differentiation of developing dopamine systems. Neuroscience. 2016;333:193-203.

87. Brown AS, Patterson PH. Maternal infection and schizophrenia: implications for prevention. Schizophr Bull. 2011;37:284-90.

88. Peelen E, Knippenberg S, Muris AH, Thewissen M, Smolders J, Tervaert JW, et al. Effects of vitamin D on the peripheral adaptive immune system: a review. Autoimmun Rev. 2011;10:733-43.

89. Ali A, Cui X, Alexander S, Eyles D. The placental immune response is dysregulated developmentally vitamin $\mathrm{D}$ deficient rats: relevance to autism. J Steroid Biochem Mol Biol. 2018;180:73-80.

90. Ursini G, Punzi G, Chen Q, Marenco S, Robinson JF, Porcelli A, et al. Convergence of placenta biology and genetic risk for schizophrenia. Nat Med. 2018;24:792-801.

91. Tesic D, Hawes JE, Zosky GR, Wyrwoll CS. Vitamin D deficiency in $\mathrm{BALB} / \mathrm{c}$ mouse pregnancy increases placental transfer of glucocorticoids. Endocrinology. 2015;156:3673-9.

92. Koenig JI, Kirkpatrick B, Lee P. Glucocorticoid hormones and early brain development in schizophrenia. Neuropsychopharmacology. 2002;27:309-18.

93. Eyles DW, Rogers F, Buller K, McGrath JJ, Ko P, French K, et al. Developmental vitamin D (DVD) deficiency in the rat alters adult behaviour independently of HPA function. Psychoneuroendocrinology. 2006;31:958-64.

94. Yates NJ, Tesic D, Feindel KW, Smith JT, Clarke MW, Wale C, et al. Vitamin D is crucial for maternal care and offspring social behaviour in rats. J Endocrinol. 2018;237:73-85.

95. Ali A, Vasileva S, Langguth M, Alexander S, Cui X, Whitehouse A, et al. Developmental vitamin D deficiency produces behavioral phenotypes of relevance to Autism in an animal model. Nutrients. 2019;11:1187.

96. Burne TH, O’Loan J, Splatt K, Alexander S, McGrath JJ, Eyles DW. Developmental vitamin D (DVD) deficiency alters pupretrieval but not isolation-induced pup ultrasonic vocalizations in the rat. Physiol Behav. 2011;102:201-4.

97. Burne TH, Feron F, Brown J, Eyles DW, McGrath JJ, MackaySim A. Combined prenatal and chronic postnatal vitamin D deficiency in rats impairs prepulse inhibition of acoustic startle. Physiol Behav. 2004;81:651-5.

98. Becker A, Eyles DW, McGrath JJ, Grecksch G. Transient prenatal vitamin $\mathrm{D}$ deficiency is associated with subtle alterations in learning and memory functions in adult rats. Behav Brain Res. 2005;161:306-12.

99. Turner KM, Young JW, McGrath JJ, Eyles DW, Burne TH. Cognitive performance and response inhibition in developmentally vitamin D (DVD)-deficient rats. Behav Brain Res. 2013;242:47-53.

100. Kesby JP, Burne TH, McGrath JJ, Eyles DW. Developmental vitamin D deficiency alters MK 801-induced hyperlocomotion in the adult rat: an animal model of schizophrenia. Biol Psychiatry. 2006;60:591-6. 
101. O’Loan J, Eyles DW, Kesby J, Ko P, McGrath JJ, Burne TH. Vitamin D deficiency during various stages of pregnancy in the rat; its impact on development and behaviour in adult offspring. Psychoneuroendocrinology. 2007;32:227-34.

102. Kesby JP, O'Loan JC, Alexander S, Deng C, Huang XF, McGrath JJ, et al. Developmental vitamin D deficiency alters MK-801-induced behaviours in adult offspring. Psychopharmacology. 2012;220:455-63.

103. Kesby JP, Cui X, O'Loan J, McGrath JJ, Burne TH, Eyles DW. Developmental vitamin D deficiency alters dopamine-mediated behaviors and dopamine transporter function in adult female rats. Psychopharmacology. 2010;208:159-68.

104. Grecksch G, Ruthrich H, Hollt V, Becker A. Transient prenatal vitamin $\mathrm{D}$ deficiency is associated with changes of synaptic plasticity in the dentate gyrus in adult rats. Psychoneuroendocrinology. 2009;34:258-264.

105. Al-Harbi AN, Khan KM, Rahman A. Developmental vitamin D deficiency affects spatial learning in Wistar rats. J Nutr. 2017;147:1795-805.

106. Harms LR, Turner KM, Eyles DW, Young JW, McGrath JJ, Burne TH. Attentional processing in C57BL/6J mice exposed to developmental vitamin D deficiency. PLoS ONE. 2012;7: e35896.

107. Langguth M, Fassin M, Alexander S, Turner KM, Burne THJ. No effect of prenatal vitamin D deficiency on autism-relevant behaviours in multiple inbred strains of mice. Behav Brain Res. 2018;348:42-52.

108. Feron F, Burne TH, Brown J, Smith E, McGrath JJ, Mackay-Sim A, et al. Developmental Vitamin $\mathrm{D}_{3}$ deficiency alters the adult rat brain. Brain Res Bull. 2005;65:141-8.

109. McGrath J, Iwazaki T, Eyles D, Burne T, Cui X, Ko P, et al. Protein expression in the nucleus accumbens of rats exposed to developmental vitamin D deficiency. PLoS ONE. 2008;3:e2383.

110. Keilhoff G, Grecksch G, Becker A. Haloperidol normalized prenatal vitamin $\mathrm{D}$ depletion-induced reduction of hippocampal cell proliferation in adult rats. Neurosci Lett. 2010;476:94-8.

111. Luan W, Hammond LA, Vuillermot S, Meyer U, Eyles DW. Maternal vitamin D prevents abnormal dopaminergic development and function in a mouse model of prenatal immune activation. Sci Rep. 2018;8:9741.

112. Jiang P, Zhang LH, Cai HL, Li HD, Liu YP, Tang MM, et al. Neurochemical effects of chronic administration of calcitriol in rats. Nutrients. 2014;6:6048-59.

113. Brewer LD, Thibault V, Chen KC, Langub MC, Landfield PW, Porter NM. Vitamin D hormone confers neuroprotection in parallel with downregulation of L-type calcium channel expression in hippocampal neurons. J Neurosci. 2001;21:98-108.

114. Gezen-Ak D, Dursun E, Yilmazer S. The effects of vitamin D receptor silencing on the expression of LVSCC-A1C and LVSCC-A1D and the release of NGF in cortical neurons. PLoS ONE. 2011;6:e17553.

115. Schurhoff F, Szoke A, Chevalier F, Roy I, Meary A, Bellivier F, et al. Schizotypal dimensions: an intermediate phenotype associated with the COMT high activity allele. Schizophr Res. 2006;81:223.

116. Shifman S, Bronstein M, Sternfeld M, Pisante-Shalom A, LevLehman E, Weizman A, et al. A highly significant association between a COMT haplotype and schizophrenia. Am J Hum Genet. 2002;71:1296-302.

117. Ripke S, Schizophrenia Working Group of the Psychiatric Genomics Consortium. Biological insights from 108 schizophrenia-associated genetic loci. Nature. 2014;511:421-7.

118. Oda Y, Sihlbom C, Chalkley RJ, Huang L, Rachez C, Chang CP, et al. Two distinct coactivators, DRIP/mediator and SRC/p160, are differentially involved in vitamin $\mathrm{D}$ receptor transactivation during keratinocyte differentiation. Mol Endocrinol. 2003;17:2329-39.

119. Liao L, Chen X, Wang S, Parlow AF, Xu J. Steroid receptor coactivator 3 maintains circulating insulin-like growth factor I (IGF-I) by controlling IGF-binding protein 3 expression. Mol Cell Biol. 2008;28:2460-9.

120. Lee JW, Cheong JH, Lee YC, Na SY, Lee SK. Dissecting the molecular mechanism of nuclear receptor action: transcription coactivators and corepressors. Exp Mol Med. 2000;32:53-60.

121. Malinen M, Saramaki A, Ropponen A, Degenhardt T, Vaisanen $\mathrm{S}$, Carlberg C. Distinct HDACs regulate the transcriptional response of human cyclin-dependent kinase inhibitor genes to Trichostatin $\mathrm{A}$ and 1alpha,25-dihydroxyvitamin $\mathrm{D}_{3}$. Nucleic Acids Res. 2008;36:121-32.

122. Polly P, Herdick M, Moehren U, Baniahmad A, Heinzel T, Carlberg C. VDR-Alien: a novel, DNA-selective vitamin D(3) receptor-corepressor partnership. FASEB J. 2000;14:1455-63.

123. Jepsen K, Solum D, Zhou T, McEvilly RJ, Kim HJ, Glass CK, et al. SMRT-mediated repression of an H3K27 demethylase in progression from neural stem cell to neuron. Nature. 2007;450:415-9.

124. Choi M, Yamada S, Makishima M. Dynamic and ligandselective interactions of vitamin $\mathrm{D}$ receptor with retinoid $\mathrm{X}$ receptor and cofactors in living cells. Mol Pharmacol. 2011;80:1147-55.

125. Khanim FL, Gommersall LM, Wood VH, Smith KL, Montalvo L, O'Neill LP, et al. Altered SMRT levels disrupt vitamin $\mathrm{D}_{3}$ receptor signalling in prostate cancer cells. Oncogene. 2004;23:6712-25.

126. Broekema MF, Hollman DAA, Koppen A, van den Ham HJ, Melchers D, Pijnenburg D, et al. Profiling of 3696 nuclear receptor-coregulator interactions: a resource for biological and clinical discovery. Endocrinology. 2018;159:2397-407.

127. Sun Z, Xu Y. Nuclear receptor coactivators (NCOAs) and corepressors (NCORs) in the brain. Endocrinology. 2020;161:1-12.

128. Li B, Chik CL, Taniguchi N, Ho AK, Karpinski E. 24,25(OH)2 vitamin $\mathrm{D}_{3}$ modulates the L-type $\mathrm{Ca} 2+$ channel current in UMR 106 cells: involvement of protein kinase $\mathrm{A}$ and protein kinase $\mathrm{C}$. Cell Calcium. 1996;19:193-200.

129. Morelli S, de Boland AR, Boland RL. Generation of inositol phosphates, diacylglycerol and calcium fluxes in myoblasts treated with 1,25-dihydroxyvitamin $\mathrm{D}_{3}$. Biochem J. 1993;289:675-9.

130. Kajikawa M, Ishida H, Fujimoto S, Mukai E, Nishimura M, Fujita J, et al. An insulinotropic effect of vitamin D analog with increasing intracellular $\mathrm{Ca} 2+$ concentration in pancreatic betacells through nongenomic signal transduction. Endocrinology. 1999;140:4706-12.

131. Hii CS, Ferrante A. The non-genomic actions of Vitamin D. Nutrients. 2016;8:135.

132. Gooch H, Cui X, Anggono V, Trzaskowski M, Tan MC, Eyles DW, et al. 1,25-Dihydroxyvitamin D modulates L-type voltagegated calcium channels in a subset of neurons in the developing mouse prefrontal cortex. Transl Psychiatry. 2019;9:281.

133. Gezen-Ak D, Dursun E, Yilmazer S. Vitamin D inquiry in hippocampal neurons: consequences of vitamin D-VDR pathway disruption on calcium channel and the vitamin $\mathrm{D}$ requirement. Neurol Sci. 2013;34:1453-8.

134. Dedic N, Pohlmann ML, Richter JS, Mehta D, Czamara D, Metzger MW, et al. Cross-disorder risk gene CACNA1C differentially modulates susceptibility to psychiatric disorders during development and adulthood. Mol Psychiatry. 2018;23:533-43.

135. Groves NJ, Kesby JP, Eyles DW, McGrath JJ, Mackay-Sim A, Burne TH. Adult vitamin D deficiency leads to behavioural and brain neurochemical alterations in $\mathrm{C} 57 \mathrm{BL} / 6 \mathrm{~J}$ and $\mathrm{BALB} / \mathrm{c}$ mice. Behav Brain Res. 2013;241:120-31. 
136. Kasatkina LA, Tarasenko AS, Krupko OO, Kuchmerovska TM, Lisakovska OO, Trikash IO. Vitamin D deficiency induces the excitation/inhibition brain imbalance and the proinflammatory shift. Int J Biochem Cell Biol. 2020;119:105665.

137. Al-Amin MM, Sullivan RKP, Kurniawan ND, Burne THJ. Adult vitamin $\mathrm{D}$ deficiency disrupts hippocampal-dependent learning and structural brain connectivity in BALB/c mice. Brain Struct Funct. 2019;224:1315-29.

138. Sorg BA, Berretta S, Blacktop JM, Fawcett JW, Kitagawa H, Kwok JC, et al. Casting a wide net: role of perineuronal nets in neural plasticity. J Neurosci. 2016;36:11459-68.

139. Steullet P, Cabungcal JH, Cuenod M, Do KQ. Fast oscillatory activity in the anterior cingulate cortex: dopaminergic modulation and effect of perineuronal net loss. Front Cell Neurosci. 2014;8:244.

140. Byrne JH, Voogt M, Turner KM, Eyles DW, McGrath JJ, Burne TH. The impact of adult vitamin D deficiency on behaviour and brain function in male Sprague-Dawley rats. PLoS ONE. 2013;8: e71593.

141. Trinko JR, Land BB, Solecki WB, Wickham RJ, Tellez LA, Maldonado-Aviles J. et al. Vitamin $\mathrm{D}_{3}$ : a role in dopamine circuit regulation, diet-Induced obesity, and drug consumption. eNeuro. 2016;3:e122-0115.

142. Taghizadeh M, Talaei SA, Salami M. Vitamin D deficiency impairs spatial learning in adult rats. Iran Biomed $\mathrm{J}$. 2013;17:42-8.

143. Latimer CS, Brewer LD, Searcy JL, Chen KC, Popovic J, Kraner $\mathrm{SD}$, et al. Vitamin D prevents cognitive decline and enhances hippocampal synaptic function in aging rats. Proc Natl Acad Sci USA. 2014;111:E4359-66.

144. Groves NJ, Burne TH. Sex-specific attentional deficits in adult vitamin D deficient BALB/c mice. Physiol Behav. 2016;157:94-101.

145. Suzuki M, Yoshioka M, Hashimoto M, Murakami M, Noya M, Takahashi D, et al. Randomized, double-blind, placebo- controlled trial of vitamin D supplementation in Parkinson disease. Am J Clin Nutr 2013;97:1004-13.

146. Cui X, Groves NJ, Burne TH, Eyles DW, McGrath JJ. Low vitamin D concentration exacerbates adult brain dysfunction. Am J Clin Nutr. 2013;97:907-8.

147. Eyles D, Feldon J, Meyer U. Schizophrenia: do all roads lead to dopamine or is this where they start? Evidence from two epidemiologically informed developmental rodent models. Trans Psychiatry. 2012;2:e81.

148. Vuillermot S, Luan W, Meyer U, Eyles D. Vitamin D treatment during pregnancy prevents autism-related phenotypes in a mouse model of maternal immune activation. Mol Autism. 2017;8:9.

149. Melamed ML, Michos ED, Post W, Astor B. 25-hydroxyvitamin $\mathrm{D}$ levels and the risk of mortality in the general population. Arch Intern Med. 2008;168:1629-37.

150. Berk M, Jacka FN, Williams LJ, Ng F, Dodd S, Pasco JA. Is this D vitamin to worry about? Vitamin D insufficiency in an inpatient sample. Aust NZ J Psychiatry. 2008;42:874-8.

151. Balden R, Selvamani A, Sohrabji F. Vitamin D deficiency exacerbates experimental stroke injury and dysregulates ischemia-induced inflammation in adult rats. Endocrinology. 2012;153:2420-35.

152. Hanel A, Carlberg C. Skin colour and vitamin D: an update. Exp Dermatol. 2020. https://doi.org/10.1111/exd.14142.

153. Krisanova N, Pozdnyakova N, Pastukhov A, Dudarenko M, Maksymchuk O, Parkhomets $\mathrm{P}$, et al. Vitamin $\mathrm{D}_{3}$ deficiency in puberty rats causes presynaptic malfunctioning through alterations in exocytotic release and uptake of glutamate/GABA and expression of EAAC-1/GAT-3 transporters. Food Chem Toxicol. 2019;123:142-50.

154. Overeem K, Alexander S, Burne THJ, Ko P, Eyles DW. Developmental vitamin D deficiency in the rat Impairs recognition memory, but has no effect on social approach or hedonia. Nutrients. 2019;11:2713. 